\title{
THE USEFULNESS OF ARCHIVAL CARTOGRAPHIC MATERIALS IN THE LEGAL CLASSIFICATION OF LAKES IN POLAND
}

\author{
W. MARSZELEWSKI ${ }^{1}$, S. BRÓZDA ${ }^{1}$, M. MARSZELEWSKI ${ }^{2}$
}

\begin{abstract}
The study documents usefulness of archival cartographic materials for the classification of lakes in accordance with the Polish law. The differences in the hydrological and normative classifications of lakes are, therefore, discussed. Moreover, special attention was drawn to diverse presentation of the elements of the hydrographic network in the individual maps. Despite the established high usefulness of maps for the classification of lakes, field observations are recommended to verify the conclusions formed on the grounds of desk studies.
\end{abstract}

Keywords: classification of lakes, hydrography, Water law, Polish law.

\section{INTRODUCTION}

For many years lakes have been subject to civil law provided they were classified as stagnant waters. One of the main reasons for the desire to own lakes is the economic aspect related to, among others, the possibility to run fish farms. In recent years lakes have been purchased more often for recreational purposes. For approximately 100 years, however, legal regulations governing the terms of purchase and sale (i.e. the conduct of civil law transactions) have changed. In the case of Poland, the biggest and fastest legal changes occurred in the twentieth century. It was possible to purchase a lake regardless of its hydrological type in the first half of the twentieth century. Since the mid-twentieth century several legal regulations have been introduced. Currently, a closed lake or an open lake (an open lake only with an artificial inflow and/or outflow can constitute a private property Art. 5 section 3 item $1 \mathrm{~b}$, Water Law Act of 2001). The introduction of the term of an artificial inflow and/or outflow to the Polish legislation has caused serious legal complications and disputes (K.Kubiak-Wójcicka, M.Marszelewski 2012; M.Marszelewski, W.Marszelewski 2013). This results from the fact that most watercourses, particularly small ones, have been strongly changed due to longlasting anthropologic activity. In addition, a lot of new ditches were dug as part of drainage works. In recent years, artificial watercourses (including ditches) became similar to natural watercourses. As a result, in many cases it is difficult to assess the true nature of the watercourse, especially to an office worker who tends to classify a lake. The study aims to prove usefulness of archival maps for

${ }^{1}$ Nicolaus Copernicus University in Toruń, Faculty of Earth Sciences, Department of Hydrology and Water Managemnet, ul. Lwowska 1, 87-100 Toruń, Poland, e-mail: marszel@umk.pl; slawomirb@dremex.com.pl

2 Nicolaus Copernicus University in Toruń, Faculty of Law and Administration, Department of Insurance Law, ul. Bojarskiego 3, 87-100 Toruń, Poland, e-mail: marszelewski@gmail.com 
determining the nature of a lake, and to draw attention to problems arising when the maps are inaccurate.

\section{HYDROLOGICAL AND LEGAL CLASSIFICATION OF LAKES}

In order to determine a hydrological type of the lake, its location in the hydrological network is taken into consideration, particularly with relation to watercourses. There are two main hydrological types: open lakes and closed lakes. An open lake (an exorheic lake) is a lake where water constantly flows out. The open lake group can be divided into those lakes having an inflow and outflow (flow open lakes), and those lakes having only an outflow (outflow open lakes). Whereas a closed lake (or endorheic lake) is a lake without an outflow or which has insignificant outflow. Therefore, the hydrological type of the lake depends upon the relations between a lake and a watercourse, and it is not essential whether a watercourse is natural or artificial. From a hydrological point of view, water inflow to the lake is important, as well as the related quantitative and qualitative effect. Thus, the genesis of the watercourse flowing into the lake is not significant. The briefly presented hydrological classification does not account for underground supply of the lakes which is sometimes more important than the supply with surface waters.

While determining the legal classification of a lake (in accordance with the Water Law Act of 2001) the existence (or lack) of the surface continuous or periodic inflow or outflow should be taken into account. This inflow or outflow must be of a natural origin. Hence, if a natural watercourse flows into or out of the lake, the lake is recognized in law as flowing water. If an artificial watercourse flows into or out of the lake, the lake is recognized in law as stagnant water (Art. 5 section 3 item 2). Each lake classified as flowing water is the property of the State Treasury and cannot be traded in civil law, and consequently cannot constitute a private property (Art.10 section 3). Whereas the lake legally classified as stagnant water, may constitute a private property, and belong to a natural or legal person.

The above facts indicate that the appropriate assessment of the nature of the lake's inflow or outflow is important. This assessment is most frequently carried out based on the results of desk work which involves the analysis of various documents, including maps.

\section{CARTOGRAPHIC MATERIALS AS ONE OF THE METHODS TO CLASSIFY LAKES IN LEGAL TERMS}

The hydrographic map of Poland at the scale of 1: 50000 is one of the fundamental cartographic documents. In some cases, however, it turns out that the hydrographic situation in the map does not fully correspond to the actual situation. Lake Stacino in the Pomeranian Lakeland serves as an example. According to the information in the hydrographic map, continuous watercourses flow into and out of 
the lake. Moreover, it was initially assumed that these watercourses were natural as the scale of map did not allow further differentiation. As a result, the lake was classified as flowing water (Fig. 1). Therefore, in order to obtain the certainty in such a situation, other older maps, also topographic ones should be reviewed.

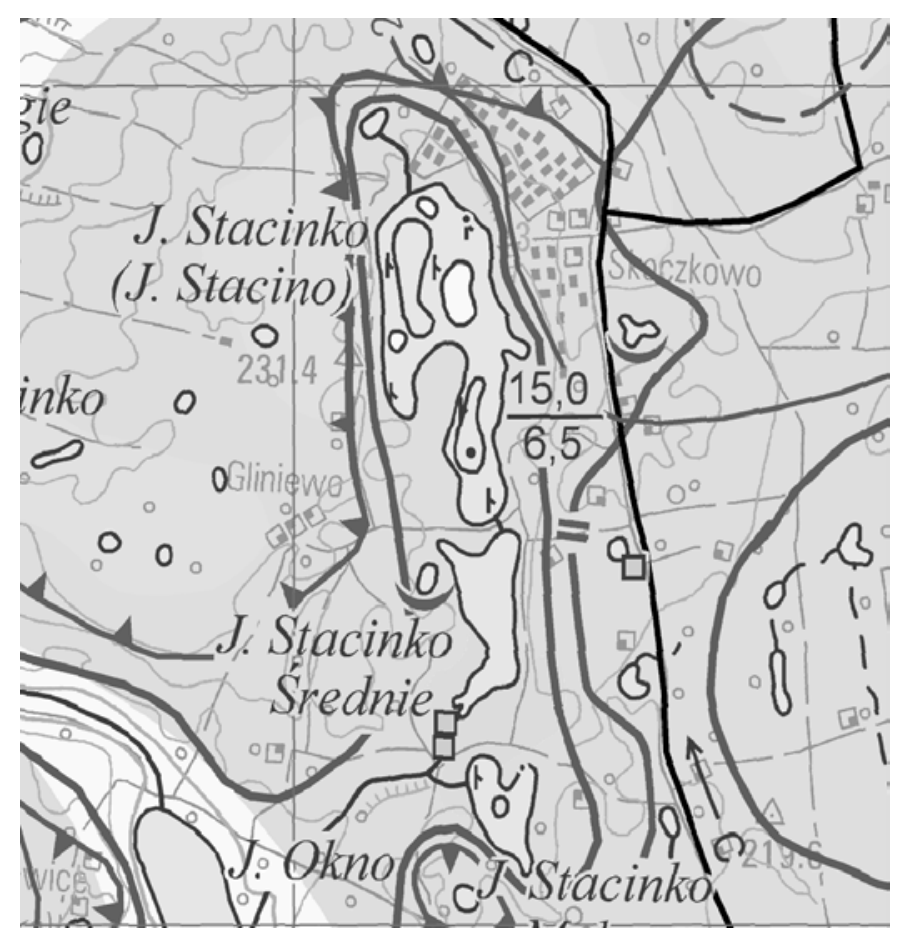

Fig. 1. A fragment of the hydrographic map at the scale 1:50000 sheet Stęzyca dating from 2006 (source: Polkart, Warsaw).

The 1976 topographic map indicates Lake Stacino has an inflow, whereas there is no outflow (Fig. 2 A). Hence, significant discrepancy was found in the case of the "missing" outflow. Nonetheless, the lake should be classified as flowing water in legal terms.

The 1962 topographic map is another cartographic document (Fig. 2 B), according to which the analysed lake has neither an inflow nor outflow. Thus, it meets the criteria for the lake to be classified as stagnant water within the meaning of the Water Law Act of 2001.

The analysis of the above mentioned maps does not lead to a clear classification of the nature of the lake. Each map contains different information on the position of the lake in the hydrographic network. Therefore, further reviews of cartographic documents appear essential as the Pomerania region has accurate documentation in the form of the maps at the scale of 1:25000 dating from the nineteenth century. 

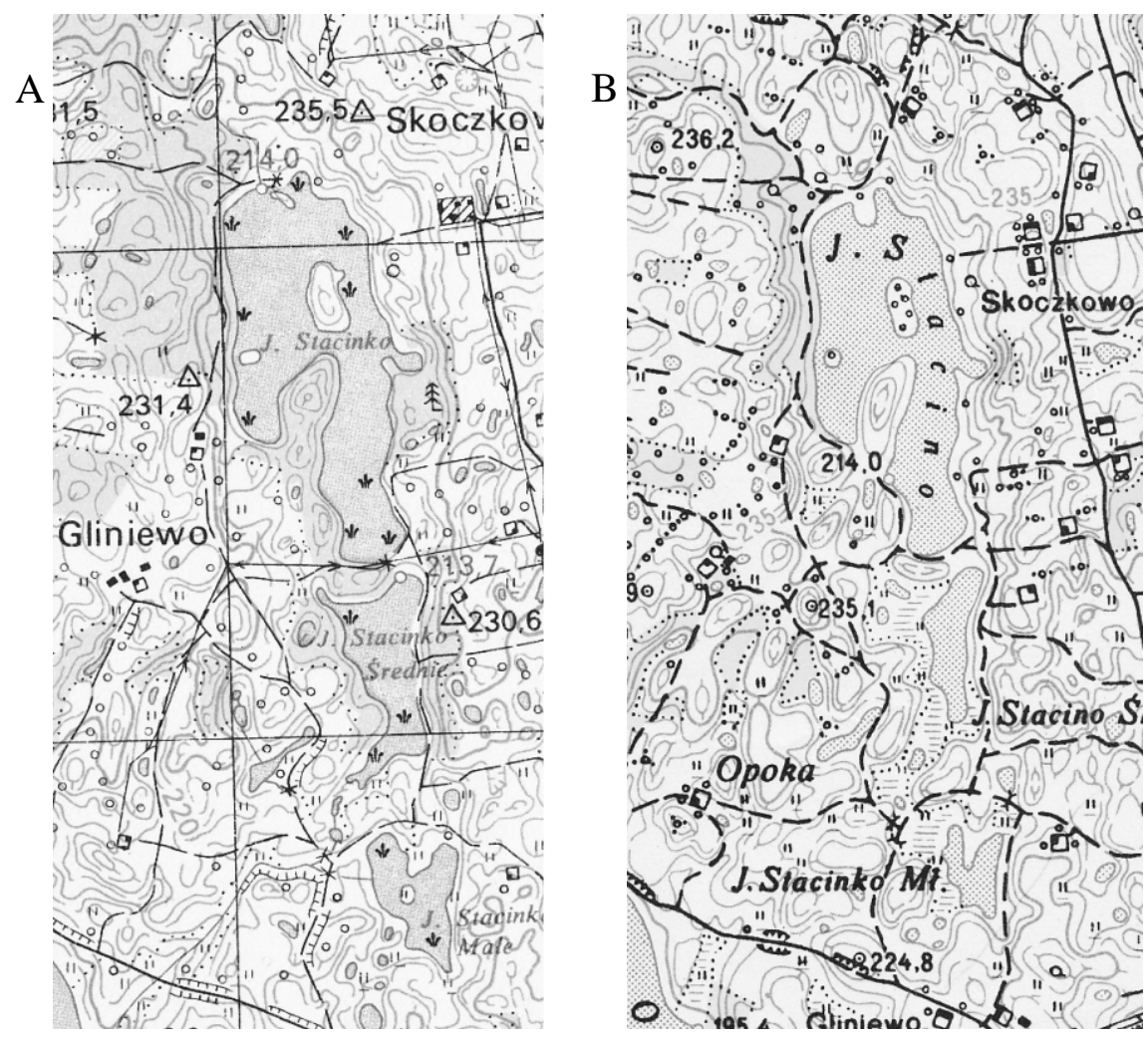

Fig. 2. The fragments of the topographic maps at the scale 1:25000 sheet Stęzyca dating from 1976 (A) and from 1962 (B). Source: the cartographic resources of the Faculty of Earth Sciences of the Nicolaus Copernicus University in Toruń.

The German topographic maps (Messtischblatt ${ }^{2}$ ) at the scale of 1:25000 - the sheet of Sierakowitz (Sierakowice) - dating from 1877 and 1935 indicates Lake Stacino does not have any inflow or outflow (Fig. 3). The conclusion arising from the 1962 topographic map confirms this. Moreover, the older map (from 1877) shows Lake Stacino as one big water body comprising all three currently existing lakes. Thus, Lake Stacino developed from the division of a bigger lake into three smaller ones. This division resulted from drainage works conducted on a big scale in this area starting from the latter half of the nineteenth century. These drainage works were carried out in order to dry wetlands as the water levels around the lakes declined, and to provide new meadows for grazing animals. Such transformations of the water network are documented in the maps dating from

\footnotetext{
${ }^{2}$ Messtischblatt - the German topographic map at the scale of 1:25000, shows very big accuracy and precision in mapping the topography. Messtischblatt maps were published from the late nineteenth century to 1944.
} 
1877 and 1935 . The 1877 map shows there used to be vast areas of wetlands around one Lake Stacino. Whereas, there are no wetlands there in the 1935 map, and the lake was split into two parts with a road between them. The watercourse joining the present Lake Stacino with the lake located lower is a result of an anthropogenic activity. During this time there was no record of any other watercourse flowing into the lake.
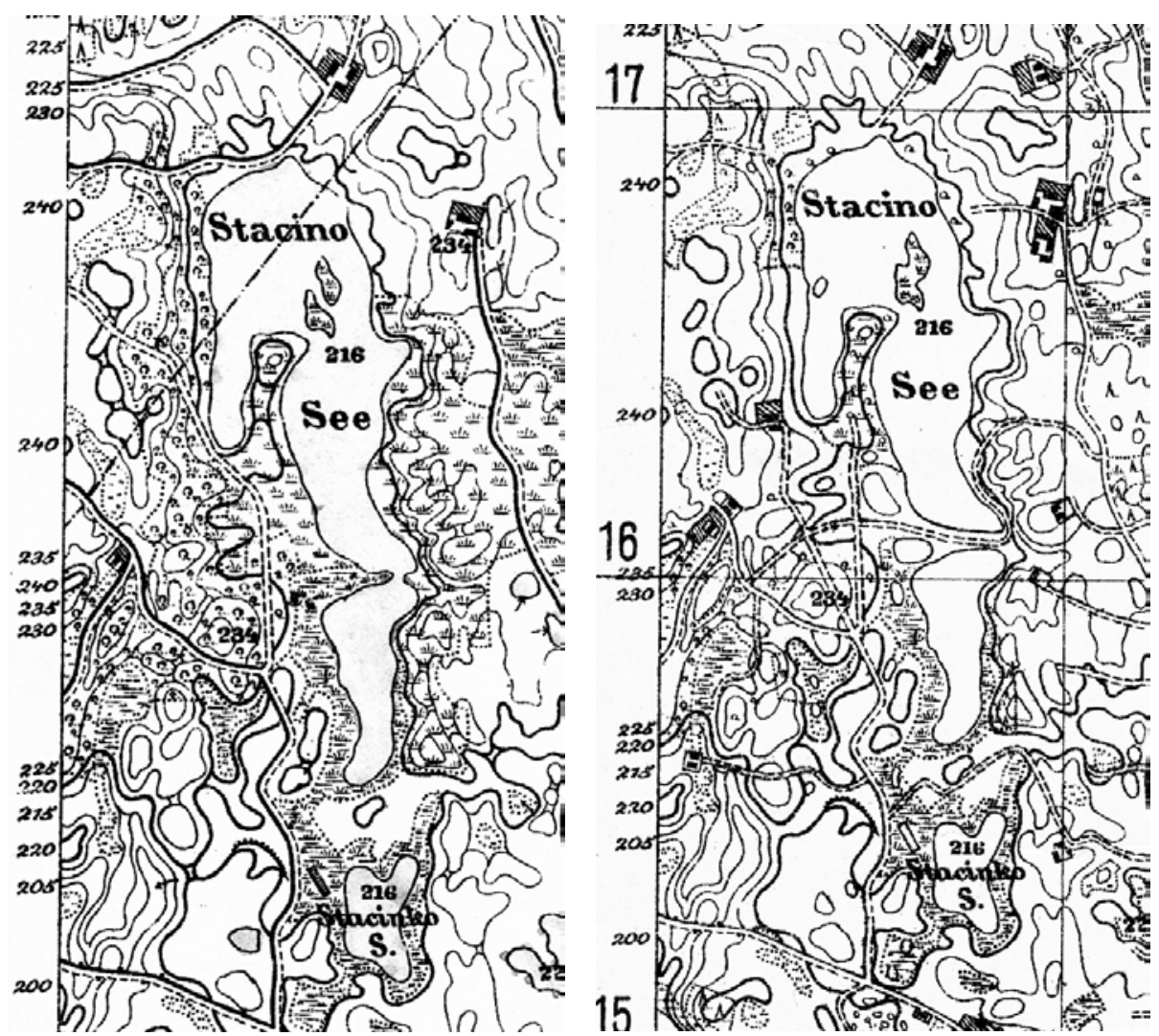

Fig. 3. The fragments of the German topographic maps (Messtischblatt) at the scale 1:25000 sheet Sierakowitz (Sierakowice) dating from 1877 (the left map) and from 1935 (the right map). Source: the cartographic resources of the Faculty of Earth Sciences of the Nicolaus Copernicus University in Toruń.

In the case of Lake Stacino, there is another significant document which confirms the fact it was divided into several parts due to drainage works. It is the Prussian map dating from 1796-1802 prepared using the method of hatching (Fig. 4). This map clearly shows the analysed lake as closed, and located in a well-defined basin, currently called a postglacial channel. 


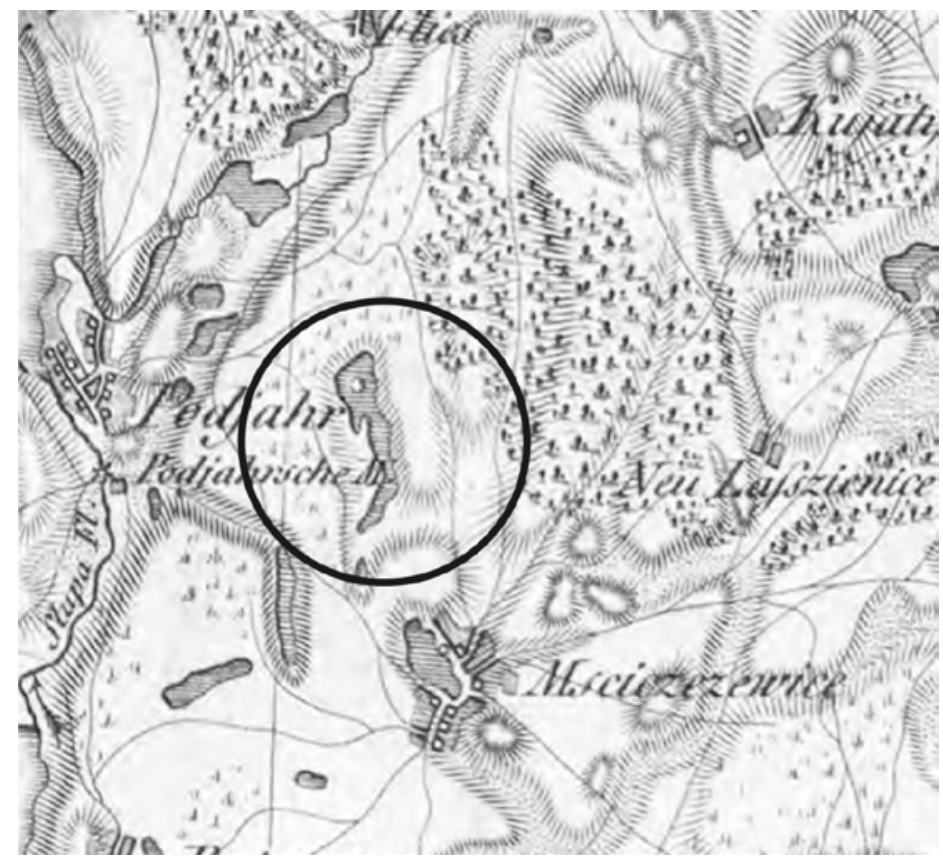

Fig. 4. A fragment of the Prussian map dating from 1796 - 1802 (Karte von Ost-Preussen nebst Preussisch Litthauen und West-Preussen nebst dem Netzdistrict aufgenommen unter Leitung des Königl. Preuss. Staats Ministers Frey Herrn von Schroetteer in den Jahren 1796 - 1802).

Source: http://rcin.org.pl/dlibra/docmetadata?id=829\&from=publication.

\section{CONCLUSIONS}

Cartographic materials constitute a very important element which facilitates the classification of lakes in accordance with the Water Law Act 2001. The authors are certain cartographic materials should not be interpreted in a selective way, which has been proven in the study. Depending on their accuracy and precision, they may present hydrographic elements in a different way, which is , in turn, vital for their classification in legal terms. In the analysed case the archival cartographic materials dating from the nineteenth century played a significant role. However, due to various historical conditions, these materials are available only for certain areas.

Despite their big importance to the legal classification of lakes, the presented cartographic materials should not constitute the only source of information on the position of the lake in the water network and its relation with watercourses. This statement results from the fact there are differences in the information presented in the individual maps. Therefore, other investigations must be conducted, including field hydrological and geomorphological observations. 
The results of all the mentioned types of studies constitute an objective material for the appropriate classification of the lake in legal terms.

\section{REFERENCES}

1. Kubiak-Wójcicka K., Marszelewski M. (2012), Definitions and evolutions of the terms "flowing and stagnant waters" in the context of the proprietorship of the lakes in Poland, Limnological Review, vol. 12(4), p. 189-195.

2. Marszelewski M., Marszelewski W. (2013), The problems concerning proprietorship of lakes in Poland, Przegląd Prawa Ochrony Środowiska, 3, p. 2945.

3. http://rcin.org.pl/dlibra/docmetadata?id=829\&from=publication. 